\title{
3 Research Square

\section{Low Bifurcation of The Left Common Carotid Artery Associated With Klippel-Feil Syndrome And Severe Stenosis of The Bilateral Proximal Middle Cerebral Artery}

Yan Li ( $\sim$ liy20210615@163.com )

Zigong First People's Hospital

Minli Lv

Zigong First People's Hospital

Jianquan Zhong

Zigong First People's Hospital

\section{Case report}

Keywords: Common carotid artery, Low bifurcation, Vascular malformation

Posted Date: September 17th, 2021

DOl: https://doi.org/10.21203/rs.3.rs-877939/v1

License: (c) (1) This work is licensed under a Creative Commons Attribution 4.0 International License.

Read Full License 


\section{Abstract}

\section{Background}

The bifurcate position of the common carotid artery is protean. It is most often locating between the C3 and $\mathrm{C} 5$ vertebral levels. Intrathoracic bifurcation of common carotid artery is a rare anatomic finding,and an association with bilateral segmental severe stenosis of middle cerebral artery has not been reported in the past literature .we report a case of low bifurcation of the left common carotid artery associated with Klippel-Feil syndrome and severe stenosis of the bilateral proximal middle cerebral artery.

\section{Case Presentation}

A 47-years old woman presented with dizziness and sleep disturbance,whose computed tomography angiography image incidentally revealed an intrathoracic bifurcation of the left common carotid artery associated with bilateral segmental severe narrowing of middle cerebral artery $\triangle \mathrm{MCA}$. The left transverse process and spinous process of C3-4 fused and posterior arch of atlas did not fuse on Volume rendered QVR】 imaging.

\section{Conclusion}

We should not only pay attention to the variation of the neck vessels, but also to the serious secondary changes of intracranial vessels caused by neck vessels variation. Low carotid bifurcation may cause chronic progressive stenosis /occlusion of the proximal MCA or severe ischemic stroke events .

\section{Background}

There are individual differences in the position of common carotid artery(CCA).It is known that the most common level of bifurcation of CCA occurs at the superior border of thyroid cartilage(C3-4 cervical vertebrae)[1-3]. Intrathoracic bifurcation of CCA is a rare vascular anomaly, with only 14 cases reported in the previous literature.As far as we know,this is the first case of an intrathoracic bifurcation of the left common carotid artery accompanied with severe stenosis of the bilateral proximal middle cerebral artery.

\section{Case Presentation}

A 47-years old woman, with normotensive and nondiabetic, presented with dizziness and sleep disturbance for 2 years and headache for one month. The low bifurcation of the left common carotid artery and left narrow internal carotid artery (ICA) was found by Doppler ultrasound (DUS) in outpatient.A few days later, she was admitted to vascular surgery in our hospital. On computed tomography angiography (CTA) ,the course and location of bifurcation right CCA is normal, Whereas the left CCA have lower bifurcation, corresponding to Th1冈Fig.1区. Left ICA had posteromedial orientation to left external carotid artery (ECA), and the lumen of left ICA and ECA was more diminutive than those on the right side. The diameter of right ICA was $5 \mathrm{~mm}$ and left one was $2 \mathrm{~mm}$. The left transverse process and spinous 
process of C3-4 fused and posterior arch of atlas did not fuse on Volume rendered (VR) imaging $\mathbb{F}$ Fig.2】.In our case, intracranial VR and Maximum Intensity Projection (MIP) also showed bilateral segmental narrowing of the middle cerebral artery (MCA $(90 \%$ and $95 \%$ on the left and right sides, respectively) (Fig.3). Lateral cervical spine X-ray imaging showed that cervical vertebrae had advanced and severe degenerative changes, not according with age(Fig.4).

\section{Discussion And Conclusions}

There are individual differences in the position of CCA.It is known that the most common level of bifurcation of CCA occurs between $\mathrm{C} 3$ and $\mathrm{C} 5$ vertebral,but uncommon locations can also appear,such as

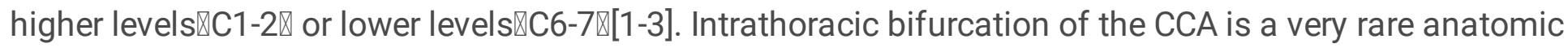
variant.There are several literature reports correlated with intrathoracic bifurcation.Intrathoracic CCA bifurcation was unilateral in ten cases and bilateral in four cases[4-6]. Level of bifurcations ranged between T1 and T4. In three cases[4, 7, 8], the early bifurcating ICA had smaller caliber compare to contralateral side, similar to our case.

In addition to the intrathoracic bifurcation of CCA,our patient also had fusion of the appendix of C3-4 vertebra and posterior arch of atlas not fusing,which was knowed as Klippel-Feil syndrome.Klippel-Feil syndrome is a rare disorder which includes the congenital fusion of at least two cervical vertebrae. The full borne spectrum is characterized by short neck, low posterior hairline, and decreased range of neck motion.In addition to,it frequently is associated with facial, osseous, cardiovascular, neurologic, and other systemic abnormalities[9].It results from faulty segmentation between 3 and 8 weeks of gestation[10].The low carotid artery bifurcation was associated with Klippel-Feil syndrome, suggesting a segmental development disorder that leads to vertebral fusion and to the third aortic arch anomaly.In our case,the reason that cervical vertebrae has advanced and severe degenerative changes might be cervical fusion abnormality.

Bilateral segmental severe narrowing of the MCA may have precipitated the dizziness in our patient despite her young age.We cannot explain the cause of the bilateral segmental severe narrowing of the MCA .A review of the published literature about Low carotid bifurcation describes neither advanced or premature atherosclerosis nor vascular wall thickening. There appear to be an association with rapid progression of a congenital vascular stenosis likely.MCA occlusion may be a late complication of the intrathoracic carotid bifurcation.

Our case shows that DUS and CTA can still be used to fully describe the rare anatomical features and provide a basis for subsequent diagnosis and treatment. We should not only pay attention to the variation of the neck vessels, but also to the serious secondary changes of intracranial vessels caused by neck vessels variation. Low carotid bifurcation may cause chronic progressive stenosis /occlusion of the proximal MCA or severe ischemic stroke events .

\section{Abbreviations}


Volume rendered $₫ \mathrm{VR}$

common carotid artery $\mathbb{C C A}$

internal carotid artery $\mathbb{\triangle} \mathrm{CA}$

Doppler ultrasound囚DUS

computed tomography angiography $\mathbb{X T A}$

external carotid artery $\mathbb{E} \mathrm{CA}$

middle cerebral artery $₫ \mathrm{MCA}$

Maximum Intensity Projection $₫$ MIP

\section{Declarations}

Ethics approval and Consent to participate $\triangle T$ This study was performed in accordance with the tenets of the Declaration of Helsinki and with the ethical standards of the Ethics committee of Zigong First People's Hospital . Consent to participate was not applicable due to the retrospective design of this study.

Consent for publication[The patient offered the consent form for publication.

Availability of data and materials₫Not applicable.

Competing interests[The authors declare that they have no competing interests.

\section{Funding $\square$ No Funding}

Authors' contributions $\square A$ All authors contributed to the study conception and design. YL and $M L$ collected and analysed patient data and figures. The first draft of the manuscript was written by YL and ML.JZ revised the manuscript.All authors commented on previous versions of the manuscript. All authors read and approved the final manuscript.

Acknowledgements:Not applicable.

\section{References}

1 Anu VR, Pai MM, Rajalakshmi R, Latha VP, Rajanigandha V, D'Costa S. Clinically-relevant variations of the carotid arterial system. Singapore Med J. 2007;48: 566-9.

2 Jitpun E, Wattanasen Y, Tirakotai W. Do Asians have Higher Carotid Bifurcation? A Computed Tomographic Angiogram Study of the Common Carotid Artery Bifurcation and External Carotid Artery Branching Patterns. Asian J Neurosurg. 2019;14: 1082-8. 
3 Kurkcuoglu A, Aytekin C, Oktem H, Pelin C. Morphological variation of carotid artery bifurcation level in digital angiography. Folia Morphol (Warsz). 2015; 74: 206-11.

4 Gailloud P, Murphy KJ, Rigamonti D. Bilateral thoracic bifurcation of the common carotid artery associated with Klippel-Feil anomaly. AJNR Am J Neuroradiol. 2000; 21: 941-4.

5 Vitek JJ, Reaves P. Thoracic bifurcation of the common carotid artery. Neuroradiology. 1973;5: 133-9.

6 Uzun L, Kokten N, Kilicaslan A, Tasel B, Kalcioglu MT, Tekin M. Bilateral lower cervical bifurcation of the common carotid artery. Case Rep Otolaryngol. 2013. 2013: 894804.

7 Gomez CK, Arnuk OJ. Intrathoracic bifurcation of the right common carotid artery. BMJ Case Rep. 2013. 2013.

8 Charalambous S, Hatzidakis A, Peteinarakis I, Megremis S, Karantanas A. Common left carotid bifurcation at C7-Th1 level: a rare anatomical variant. Surg Radiol Anat. 2019;41: 227-9.

9 Menger RP, Rayi A, Notarianni C. Klippel Feil Syndrome. 2021. Treasure Island (FL).

10 Sudhakar AS, Nguyen VT, Chang JB. Klippel-Feil syndrome and supra-aortic arch anomaly: a case report. Int J Angiol. 2008;17: 109-11.

\section{Figures}

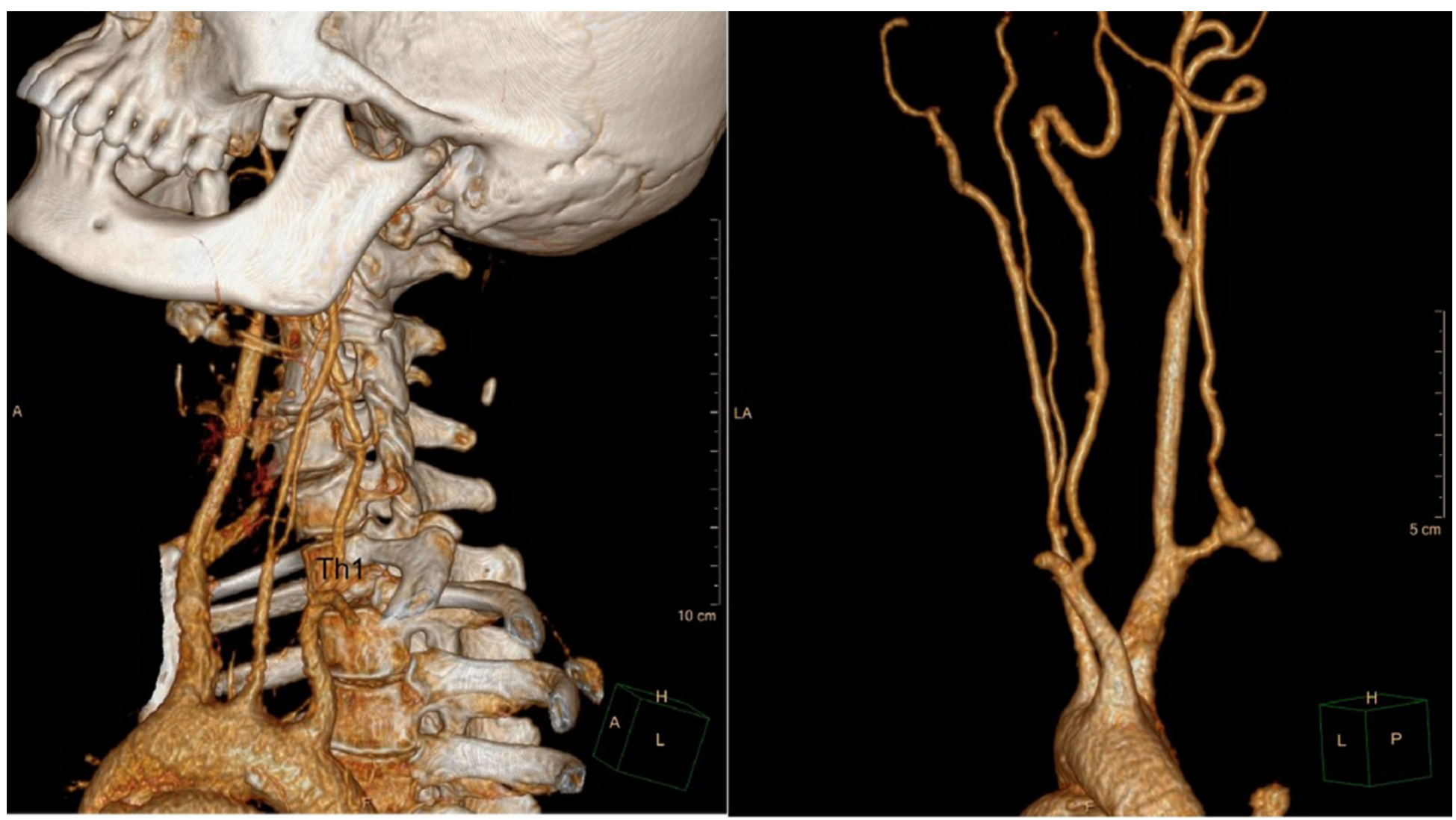




\section{Figure 1}

A left common carotid bifurcation of very low level is seen,corresponding to superior border of Th1.

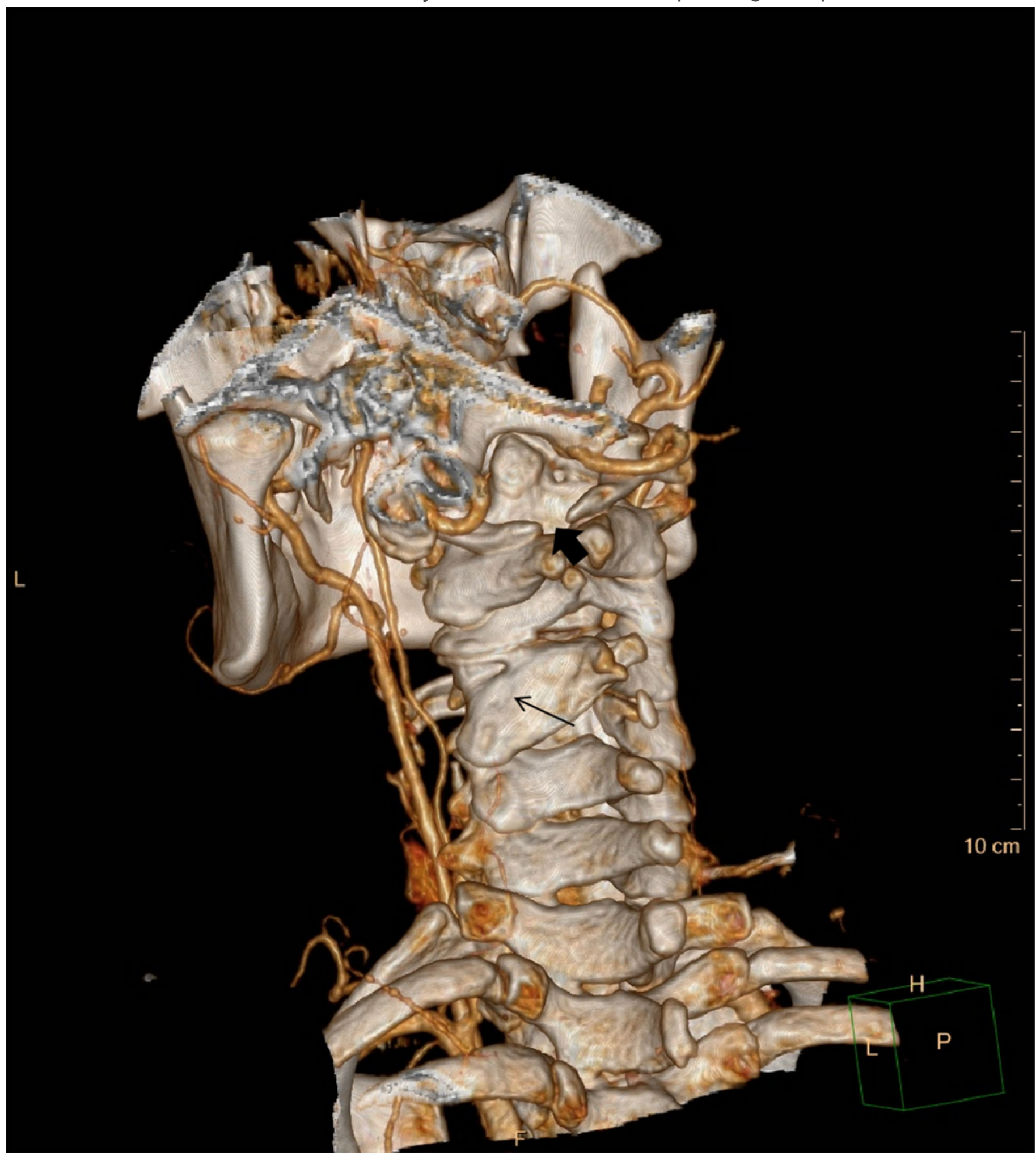

Figure 2

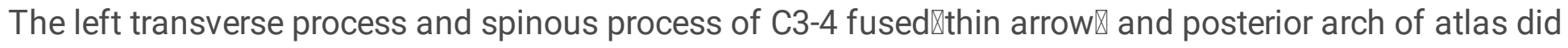
not fuse邓thick arrow $\rrbracket$ 


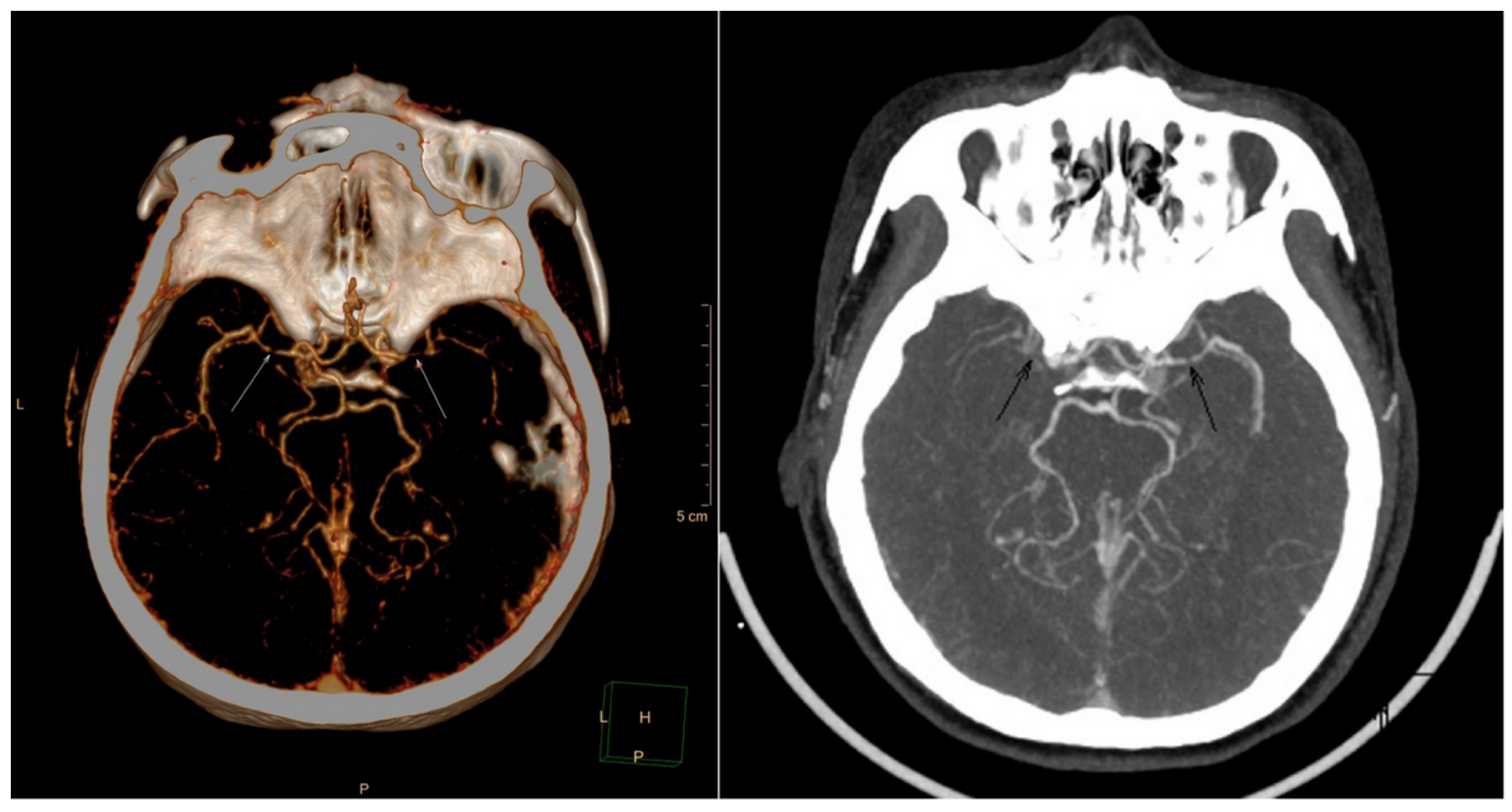

Figure 3

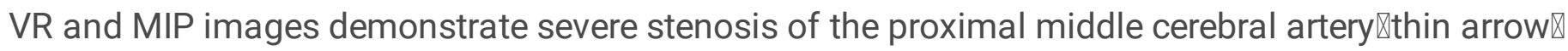




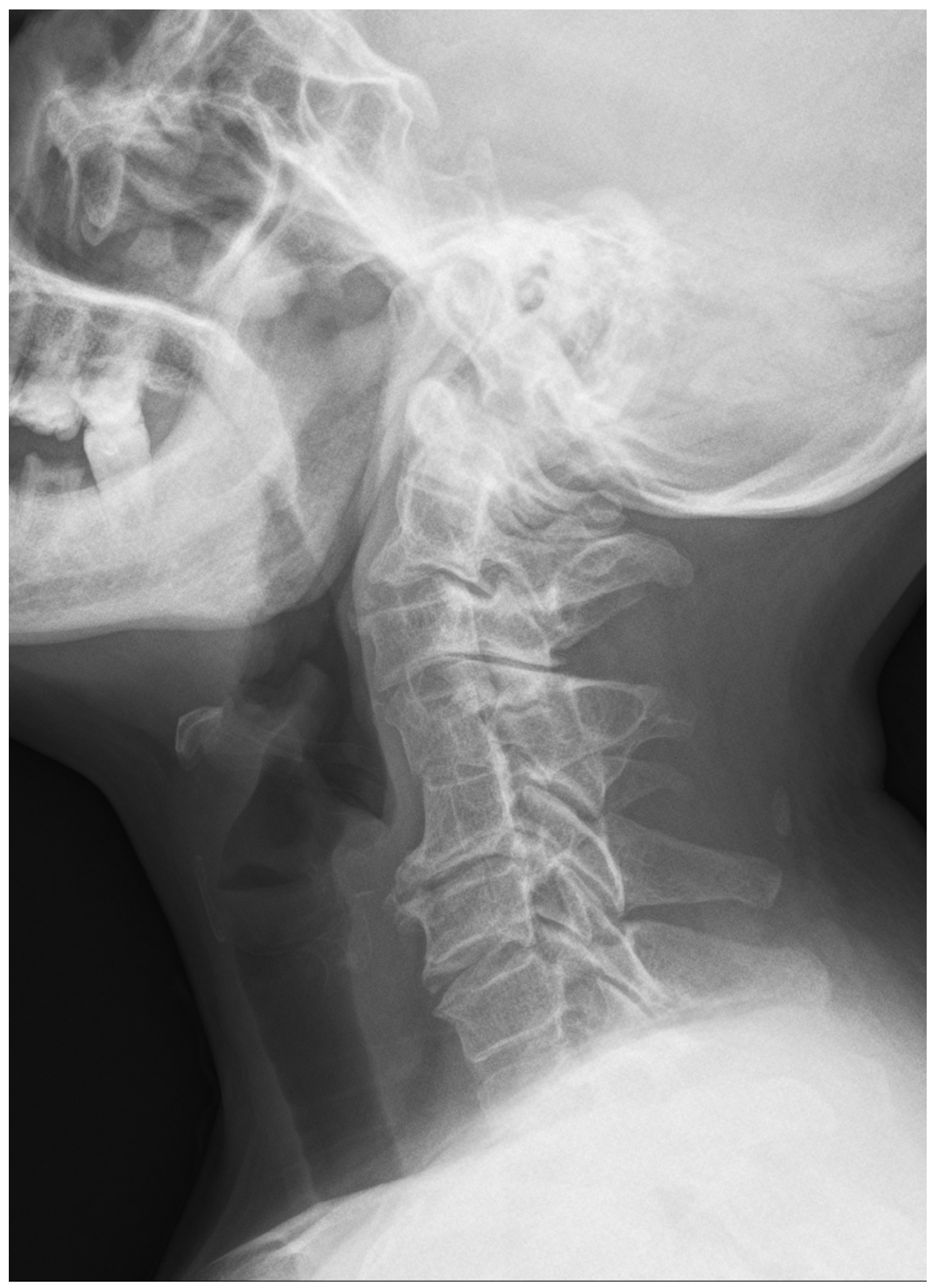

Figure 4

X-ray imaging showed Cervical vertebrae had early and severe secondary degenerative changes. 